Res Pública Revista de Historia de las Ideas Políticas

ISSN: $1131-558 \mathrm{X}$

http://dx.doi.org/10.5209/rpub.66753

\title{
Anamnesis del mundo clásico en la configuración política de los Estados Unidos de América
}

\author{
Francisco Sánchez Andrada* \\ Recibido: 03 de diciembre de 2019 / Aceptado: 25 de mayo de 2020
}

Resumen. Tomando como objetivo analizar la configuración constitucional de los Estados Unidos, se aborda la influencia que tuvo, en los padres fundadores, la teoría cultural y política heredada del mundo clásico. En este sentido, recorreremos las referencias al mundo clásico de los ideólogos de la Constitución de 1787 en relación con los aspectos simbólicos y culturales que influyeron en la conformación de la nación norteamericana a fin de aterrizar en nuestra tesis; a saber, que en la construcción de un edificio constitucional esencial en tanto paradigma de la democracia representativa y donde Montesquieu es considerado el oráculo, encontramos en los cimientos el legado de una teoría política clásica que, naciendo en Platón y Aristóteles, desemboca en Polibio.

Palabras clave: Anamnesis; Polibio; Montesquieu; Constitución de Estados Unidos; separación de poderes.

\section{[en] Anamnesis of the Classical World in the Political Configuration of the United States of America}

\begin{abstract}
Having as an objective to analyze the constitutional configuration of the United States of America, this paper deals with the influence that political and cultural theory inherited from the Classical World had in the Founding Fathers. Therefore, we will examine the references to the Classical World of the Constitution of 1787 ideologists regarding to symbolic and cultural issues which affected in shaping the United States in order to get to our thesis; namely, in the development of an essential constitutional building as paradigm of representative democracy and where Montesquieu is considered the oracle, we can find in the basis the classical political theory legacy which, being born in Plato and Aristotle, ends in Polybius.
\end{abstract}

Keywords: Anamnesis; Polybius; Montesquieu; The Constitution of the United States; Separation of Powers.

Sumario. 1. Introducción. 2. Influencia material y formal de la antigüedad clásica en el desarrollo de la nación norteamericana. 3. Constitución mixta y separación de poderes en las Historias de Polibio. 4. Montesquieu: ¿Padre de la Constitución de los Estados Unidos? 5. El oxímoron: la nueva constitución que nace en Polibio. 6. Bibliografía.

Cómo citar: Sánchez Andrada, F. (2020). Anamnesis del mundo clásico en la configuración política de los Estados Unidos de América. Res Pública. Revista de Historia de las Ideas Políticas, 23(2), 163-173.

\section{Introducción}

En el diálogo Fedro, Platón expone su teoría de la reminiscencia, donde la idea eje es la de anamnesis ${ }^{2}$, concepto que hace referencia al saber como recordar o, en términos platónicos, al diálogo del alma consigo misma. La anamnesis nos remite a la presencia de formas o modelos ya realizados en la medida en que sólo a partir de ellos podemos entender la constitución de la prolepsis; esto es, de los planes y programas presente y futuro. En palabras de Gustavo Bueno, esto "obliga a concebir el «futuro proyectado», no tanto como el acto creador o anticipador de una «fantasía mitopoiética», cuanto como un efecto de la anamnesis"3. Por lo tanto y en virtud de esta teoría, los proyectos o planes no surgen de la fantasía creadora del hombre sino del reflejo de la anamnesis.

En el presente artículo analizamos la configuración política de los Estados Unidos aplicando la teoría de la reminiscencia de Platón. No podemos comprender este desarrollo en términos filosóficos sin ahondar en los reflejos de las anamnesis que operaron, emic y etic, en los padres fundadores de la nación norteamericana. Y en este sentido, la intención de realizar un ejercicio de retrospección historiográfica nos obliga a examinar la influencia de la antigüedad clásica en los ideólogos de la revolución. Pero esto no quiere decir que el influjo sea explícito, por cuanto recurrir únicamente a muestras emic como las citas que se hicieron a obras clásicas o

\footnotetext{
Universidad Autónoma de Madrid

francisco.sanchezandrada@gmail.com

La idea de anamnesis es utilizada por Platón en diversos diálogos. Cf. Menón, Fedón, Filebo.

G. Bueno, El sentido de la vida: seis lecturas de filosofia moral, Oviedo, Grupo Helicón, 1996, p. 418.
} 
los pseudónimos grecolatinos utilizados por federalistas y antifederalistas en los debates sobre la Constitución norteamericana implicaría darse de bruces con el simplismo. Así, el objetivo del presente artículo pasa por examinar, etic, la influencia de la antigüedad clásica y particularmente de Roma desde parámetros simbólicos y materiales, pero con la idea de aterrizar en la configuración teórico-política de los Estados Unidos ${ }^{3}$.

Por lo tanto, recorremos las referencias al mundo clásico en aspectos simbólicos de la configuración de la nación norteamericana para construir la base de lo que posteriormente será nuestra tesis; a saber, que en la articulación de una doctrina constitucional que se tornó sugerente por sus elementos innovadores encontramos una estructura cuyos cimientos nos remiten a la teoría política clásica y, concretamente, a la figura de Polibio de Megalópolis. A nuestro parecer, si Montesquieu es considerado el padre ideológico de la Constitución americana en relación con el fundamento primordial de la separación de poderes, un análisis que quiera poner su punto de mira en el verdadero origen tiene que aludir al padre teórico de Montesquieu: Polibio; teniendo en cuenta, a su vez, las referencias de este, principalmente Platón y Aristóteles.

\section{Influencia material y formal de la antigüedad clásica en el desarrollo de la nación norteamericana}

Para entender la relación existente entre los intelectuales de la revolución norteamericana y la obra de los autores grecolatinos corresponde acercarse a un concepto subjetivo articulado por Joseph Levine": la "afinidad imaginaria". De esta forma, el ejemplo del mundo clásico se convirtió en un referente esencial para comprender el comportamiento ideológico de los padres fundadores. Pero, la primera pregunta a responder sería: ¿por qué estos intelectuales decidieron emplear referencias del mundo clásico como elemento catalizador de la revolución? Como nos dice Marcos Reguera, "el asunto que subyacía a la recuperación de los referentes clásicos no era otro que el del problema de la legitimidad"5. Hay que comprender, en este sentido, el contexto histórico en el que surge la revolución norteamericana; a saber, en el momento álgido de la Ilustración, donde estaba arraigado el caldo de cultivo para la caída del Antiguo Régimen y el surgimiento de los Estados-nación. Así, la

La versión que hemos empleado para citar The Federalist Papers es la que se encuentra en la biblioteca digital del Congreso de los Estados Unidos. El texto electrónico disponible fue resultado de la compilación realizada por académicos estadounidenses en el contexto del Proyecto Gutenberg. Puede accederse por medio de la siguiente URL: https://guides.loc.gov/federalist-papers/full-text. Corresponde, además, aclarar que el firmante de The Federalist, es Publius, pseudónimo que abarcaría a los tres redactores de la obra -J. Jay, A. Hamilton y J. Madison-. Aunque diversos análisis de la obra han podido identificar el autor de alguno de los papers, en el presente artículo citaremos en virtud del referido pseudónimo. Las traducciones, en su caso, son mías.

J.M. Levine, The battle of the books: history and literature in the Augustan, Ithaca (Nueva York), Cornell University Press, 1994, p. 7.

M. Reguera, "Patriotismo y romanidad en la revolución americana. El patriotismo ilustrado y su tránsito al moderno nacionalismo", Encuentro en Catay, N²6, 2012, pp. 330-341, aquí p. 336. fuente tradicional de legitimidad en el Antiguo Régimen había sido la teología política cristiana; sin embargo, en la coyuntura de las guerras interconfesionales del siglo XVIII, los fundamentos católicos habían dejado de operar como fuente de legitimidad de las nuevas estructuras estatales-nacionales, por lo que en esta maniobra de alejamiento del Estado absoluto se tornaba necesario encontrar nuevos principios legitimadores para la construcción de la nación norteamericana. En palabras de Reguera: "La antigüedad clásica ofrecía a los ilustrados, y sobre todo a los rupturistas, todo un mundo simbólico sobre el que construir una retórica de la protesta y un movimiento de resistencia para superar una época en estado terminal [...] El mundo grecorromano ofreció a los revolucionarios de finales del S. XVIII los elementos para proponer una sociedad alternativa al moribundo antiguo régimen".

El proyecto era apasionante por cuanto conllevaba la plasmación real del sueño del iluminismo europeo; esto es, levantar una nación en un acto de voluntad subjetiva popular y en un territorio virgen de historia y carente, a su vez, de los procesos culturales que arrastraba Occidente. Para ello, los padres fundadores debían crear ad hoc su estructura política y constitucional, lo que implicaba abordar la elección de las fórmulas de gobierno, del ejército y de la organización territorial del Estado de esta nueva nación. Y es aquí donde emplearon la herramienta ideológica de la república romana, elemento catalizador en la remodelación y adaptación de sus necesidades políticas y culturales.

Sin embargo, un análisis objetivo de la verdadera influencia de Roma en la configuración política y cultural norteamericana obliga a hacerse la siguiente pregunta: ¿cuál era el nivel real de conocimiento de los intelectuales de la revolución en relación con el mundo clásico y a la realidad de la República romana? Matizaremos previamente que, en el entorno educativo de estas notables figuras, el conocimiento del griego y del latín y en general de la historia de la cultura clásica era elevado. Estos expertos, instruidos en un ambiente burgués, comenzaron su formación universitaria para posteriormente recalar en el mundo político y militar de la nación incipiente. De esta forma, era inevitable que estas referencias no salieran a la luz. Los Hamilton, Madison, Adams, Washington o Jefferson envolvían ideológicamente sus escritos de la revolución aplicando, en términos platónicos, los reflejos de las anamnesis del mundo clásico.

Pero ¿quería esto decir que realmente conocían la cultura y la política de la antigüedad clásica y que la influencia real en cuestiones meramente políticas se derivaba en exclusiva del dominio greco-romano? En su obra Los orígenes de la Revolución norteamericana, Bernard Bailyn pone en cuestión esta idea. El historiador norteamericano no niega el conocimiento de estas fuentes de pensamiento por parte de los padres fundadores. No es posible afirmar tal circunstancia por cuanto quedó expresado en los documentos tanto informales como formales de la época, principalmente en los folletos de carácter discursivo y explicativo, las innumerables citas a los autores capitales de la herencia cultura

Ibidem, p. 336. 
de Occidente, desde Aristóteles a Cicerón pasando por Platón, Virgilio y Polibio. Sin embargo, la intención era inundar los textos con centenas de citas de modo decorativo a fin de otorgarles legitimidad intelectual y cultural -a lo que Baylin denominó window dressing ${ }^{7}$. Esta matización del historiador estadounidense no quiere decir que figuras como Jefferson, Adams o James Otis no fueran consumados conocedores de los textos antiguos. Otis, por ejemplo, escribió tratados de prosodia latina y griega ${ }^{8}$. Con todo, lo que reviste mayor importancia en el análisis de las lecturas de los autores clásicos por parte de los colonos es la "elevada selectividad de sus verdaderos intereses y la limitada extensión de sus conocimientos efectivos" . De hecho, a pesar de la anegación de invocaciones literales, los conocimientos específicos y el interés personal de estos autores remitían exclusivamente a épocas y escritores determinados. No obstante, esta limitación cognitiva no conlleva la inexistencia de la influencia que aquí planteamos; un influjo que, pese a este acotamiento, se tornó fundamental para entender las motivaciones ideológicas de los padres fundadores. Esta es la tesis de Gordon S. Wood cuando afirma, en The creation of the American republic 1776-1787, que el clasicismo revolucionario no operó en exclusividad como recurso estilístico de la aristocracia norteamericana, sino que ayudó a moldear sus ideas y pautas de comportamiento $^{10}$. La obra de Wood se tornó fundamental para constituir la "síntesis republicana"; esto es, la corriente historiográfica que ilustra la recuperación de los clásicos por parte de la generación revolucionaria.

$\mathrm{Y}$, ¿en qué lugar se hallaban estas influencias? A nuestro juicio, puede establecerse una taxonomía en la que se ordenen dos factores principales: en primer lugar y en consonancia con lo argumentado por autores como Bailyn y Wood, una serie de elementos de carácter sociológicos-culturales que operaron en la matriz constructiva de esta nueva cultura nacional. En segundo lugar, y en discordancia con lo expuesto por Bailyn, componentes de índole puramente políticos que, tomando forma en el ámbito greco-romano y transcurriendo en una suerte de proceso de adaptación durante la configuración de las unidades políticas de Occidente, fueron indispensables como herramientas ideológicas en la conformación política y constitucional de los Estados Unidos de América.

Comenzando por los factores sociológicos-culturales, la primera idea matriz en la formación de la nación norteamericana hace referencia al ideal rural de origen virgiliano. La retrospección a los clásicos en este sentido pasaba por conjugar un nuevo imperio donde la libertad encabezara los valores primordiales de una nación capitalista en construcción con el pastoralismo heredado de la obra de Virgilio. Fue, como nos explica Marcos Reguera, el primer leitmotiv del Partido Republicano fundado por Thomas Jefferson: un país "formado por granjeros independientes poseedores de tierras que cul-

B. Bailyn, Los origenes ideológicos de la revolución norteamericana, Madrid, Tecnos, 2012, p. 36.

Ibidem, p. 37.

Idem.

10 G.S. Wood, The creation of the American republic 1776-1787, Williamsburg, Chapel Hill, 1969, p. 49. tivasen la virtud cívica"11 como intento de "adaptar el vivere civile a la nueva coyuntura" 12 . Como explica Carl. J. Richard, los republicanos agregaron, a esta herencia conceptual pastoralista derivada del clasicismo, el liberalismo racional en ciernes en la medida en que enfatizaron la necesidad del progreso a través del esfuerzo individual ${ }^{13}$. Este ideal rural tuvo aplicación práctica en el terreno de la arquitectura, esencial para comprender la ideología cultural norteamericana. Así, este paradigma rural operó en las concepciones de los diseñadores de jardines y de todo intelectual americano, quienes se volcaron en el huerto entendiéndolo como ámbito vital y productivo. El resultado puede observarse en espacios como los jardines de Mount Vernon en la residencia de George Washington o en obras arquitectónicas de carácter civil directamente basadas en la imagen de Roma. No es casual que Jefferson bautizara el cerro donde se construyó el edificio que ocupan las dos cámaras del congreso de Estados Unidos con el nombre de Capitol Hill, inspirándose en el Capitolinus Mons de Roma, colina en la que se levantaba el templo de Iupiter Optimus Maximus.

La idea previamente esbozada de vivere civile nos lleva irremediablemente a un concepto alrededor del cual orbita la configuración sociológica de los Estados Unidos de América: el patriotismo, noción proveniente de la latinización del vocablo griego pater, conformado en Roma como patrius-a-um y que, haciendo referencia al linaje del padre, se moldeó en Roma en relación con la gens circunscrita a la tribu y parte orgánica de la civitas. Durante el Renacimiento y a fin de expresar semánticamente la idea de compromiso público, se recuperó el concepto de patriotismo en un proceso de asociación a otro término: el de vivere civile. Ya a principios del siglo XVIII y como nos dice Marcos Reguera, "patria y vivere civile se fundieron en un solo concepto: patriotismo", que unió la noción de un "territorio original entendido con carácter religioso con la idea de buen ciudadano que actúa en defensa del interés y libertad común"14.

Como última referencia sociológico-cultural hay que mencionar, como dijimos con Bailyn, las innumerables citas a autores clásicos en los folletos divulgativos sobre la Revolución. Pero no sólo fueron las alusiones, sino, por un lado, los pseudónimos utilizados tanto por los autores federalistas como por los antifederalistas y, por otro, las atribuciones personales realizadas por estos autores, quienes, como nos dice Baylin, "hallaban sus propios ideales, y hasta cierto punto, sus voces, en Bruto, en Casio y Cicerón, cuyos discursos contra Catilina [...] John Adams declamaba [...] en voz alta por las noches, a solas en su habitación"15.

Si estos son los elementos sociológico-culturales, reconocidos por cuanto las referencias al mundo clásico se tornan evidentes, en el presente artículo defendemos como tesis que, a pesar de las limitaciones cognitivas

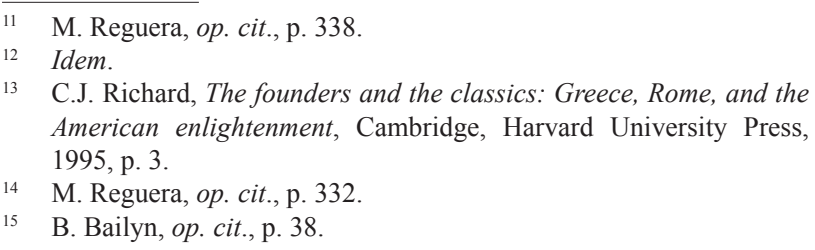


de los padres fundadores en relación con el contenido formal de las obras greco-romanas, aquellas que abordaron la teoría política operaron como base ideológica primordial en la articulación de los mecanismos constitucionales norteamericanos. Como afirma Richards, fueron los clásicos quienes suministraron las herramientas intelectuales a los padres fundadores; herramientas que se transformaron al albur del contexto histórico de la época ${ }^{16}$. De esta forma, toda vez que el análisis sobre la influencia de Polibio en la construcción de los dispositivos de la separación de poderes y checks and balances lo analizaremos en el último punto del artículo, destacaremos como fundamentos formales derivados del mundo clásico tres elementos principales.

En primer lugar, la experiencia histórica de Cromwell en Inglaterra, de la que los norteamericanos eran herederos, provocó un temor: que la revolución política contra el statu quo terminara derivando en una dictadura de carácter cesaropapista. No en vano, figuras como Washington y Adams rechazaron, en el contexto de la Revolución, ser coronados como reyes por cuanto el concepto de libertad defendido por los colonos norteamericanos convertía en incompatible que el poder lo ostentara un monarca. Como nos dice $\mathrm{M}^{\mathrm{a}}$ Diana García de Quevedo, en parte esto resultaba imposible porque "Cromwell no podía ser admirado en un país que consagró a $\mathrm{Ca}$ tón como héroe de la libertad frente a César, símbolo de la destrucción de la República"17. En segundo lugar y aunque parezca paradójico en la nación que alumbró el nacimiento de la democracia representativa, los padres de la patria aprendieron de Grecia y Roma que, más que recelar de la monarquía, había que hacerlo de la democracia; entendida, claro, como democracia directa. Así, estos intelectuales interpretaron que Atenas y Esparta fracasaron por entregarse al demos, de ahí las referencias a autores críticos con la democracia como Arístides, Aristóteles, Platón y Polibio; autores cuya teoría política descansaba en la denuncia de toda constitución simple, incluida la democrática. Como nos dice Gustavo Bueno:

Fue Platón -que no olvidaba que la democrática asamblea ateniense había condenado a muerte a Sócrates- quien atacó al núcleo mismo de la democracia periclea, es decir, la democracia procedimental, al "método racional" de tomar sus decisiones siguiendo el criterio de la mayoría [...]. La crítica de Aristóteles se mantiene en otra perspectiva que la de Platón, puesto que no deriva su crítica de su específica condición de democracia [...] sino de su condición genérica de régimen político. [...] La democracia, dice Aristóteles, es una forma más entre otras de organización de la sociedad política. Ella no garantiza su valoración (positiva o negativa) ${ }^{18}$.

Para finalizar, no podemos obviar las comparaciones con el contexto histórico-político de Grecia, donde los padres fundadores entendían que la victoria griega en las Guerras Médicas se asemejaba a la posible victoria

\footnotetext{
C.J. Richard, op. cit., p. 8.

$17 \quad$ Ma . D. García de Quevedo, "La antigua Roma y la ideología de la revolución”, Gerión, 23, 2005, pp. 329-343, aquí p. 335.

18 G. Bueno, “¿Qué es la democracia? [1]”, en El Catoblepas, 109 2011, accessible en línea en http://nodulo.org/ec/2011/n109p02.htm.
}

de los colonos sobre Inglaterra. De esta manera, las dos lecciones políticas que dedujeron fueron la primacía de las repúblicas (polis griegas-colonias americanas) sobre las monarquías (Persia-Inglaterra) y, de la posterior derrota de las polis griegas ante los imperios macedonio y romano, la necesidad de que las unidades políticas se agruparan bajo un gobierno central fuerte. Sin unión política no podía haber libertad ${ }^{19}$.

\section{Constitución mixta y separación de poderes en las Historias de Polibio}

Como venimos esbozando en el punto anterior, si hay una figura clásica que destaque como referencia en la configuración política y constitucional de los Estados Unidos es, sin duda, la de Polibio. No entraremos aquí a analizar datos biográficos del historiador de Megalópolis. Únicamente recalcaremos, por una cuestión contextual, que Polibio, griego de nacimiento, fue deportado a Roma después de la conquista de Grecia, relacionándose allí con los círculos más altos de la ciudad y especialmente con el ambiente de los Escipión. Este hecho es relevante por cuanto fue precisamente Roma $-\mathrm{y}$ no Grecia- el modelo que Polibio analizaría como ejemplo ideal de su teoría política.

Polibio aplicaría un método de carácter analítico para afirmar que el futuro de un pueblo dependía, sine qua non, de la naturaleza de su constitución; cuestión puesta de relieve en el inicio del Libro VI de las Historias: "Lo que convierte en atractivo y produce a la vez provecho a los estudiosos es la observación de las causas y la elección de lo mejor en cada caso. Por tanto, en toda cuestión debe considerarse como la causa más importante tanto del éxito como del fracaso la naturaleza de una constitución" ${ }^{20}$. En este contexto de primacía constitucional, la intención de Polibio era demostrar que el éxito de Roma, un pueblo que en menos de cincuenta y tres años venció a todos los otros Estados, radicaba precisamente en la naturaleza de su constitución. Antes de abordar los elementos constitucionales de Roma y a fin de construir la base teórica de su pensamiento, Polibio presenta tres tesis fundamentales sobre las constituciones. En primer lugar, aplica la teoría tradicional de las formas de gobierno al afirmar la existencia de seis formas de gobierno: tres buenas y tres malas ${ }^{21}$. En segundo lugar, plantea su novedosa idea de anaciclosis, en virtud de la cual estas seis formas se suceden una a la otra siguiendo un ritmo determinado, por lo que constituyen un proceso cíclico repetido en el tiempo. En tercer lugar, presenta por primera vez una teoría de gobierno mixto por medio de la cual se argumenta que, además de estas seis formas tradicionales de gobierno, existe una séptima, aplicada por Roma, que combina las tres formas

\footnotetext{
C. Martínez Maza, "Democracia ateniense vs. revolución americana: el rechazo al paradigma clásico", Potestas: Religión, poder y monarquía. Revista del Grupo Europeo de Investigación Histórica, 3, 2010, pp. 215-226, aquí pp. 218-219.

20 Polibio, Selección de historias, Madrid, Ediciones Akal, 1986, p. 156.

21 Las seis formas de gobierno según Polibio son: monarquía, aristocracia y democracia (rectas); y tiranía, oligarquía y oclocracia (torcidas).
} 
buenas para erigirse como la mejor constitución posible. Como nos dice Norberto Bobbio: "De estas tres tesis, la primera representa el uso sistemático de la teoría de las formas de gobierno, la segunda el historiográfico, la tercera el axiológico"22.

Como posteriormente veremos, estas ideas configuran un triángulo doctrinal esencial para comprender la idea de separación de poderes. Las tres tesis expuestas por Polibio revelan novedades teoréticas en su exposición. Así, en la primera de ellas, la teoría tradicional de las formas de gobierno, Polibio recogió la teoría expuesta por Platón y Aristóteles para añadir dos novedades terminológicas: denominar democracia a la tercera forma buena de gobierno -en contraposición a Aristóteles, para quien la democracia era un tipo de constitución torcida (parakbasis) - y crear, para la tercera forma mala de gobierno, el concepto de oclocracia ${ }^{23}$, proveniente de okhlos -multitud, masa-. Por otro lado, el criterio polibiano para distinguir las formas de gobierno malas de las buenas se alejó del aristotélico por cuanto no oscilaba en torno a la diferencia entre interés público y privado, sino en la diferencia entre la legitimidad basada en la fuerza y la asentada en el consenso ${ }^{24}$.

En la segunda de las tesis, la relativa a la anaciclosis o teoría de ciclos, Polibio desarrolla una cronología de origen platónico en la que las seis formas de gobierno se van alternando desde la monarquía hasta la oclocracia para completar el círculo y regresar al gobierno de uno sólo ${ }^{25}$. En este aspecto, la teoría presenta dos ideas innovadoras. En primer lugar y en comparación con lo expuesto por Platón en el Político, el ciclo de Polibio alterna una constitución buena con una mala, mientras que la serie platónica degeneraba, en orden cualitativo, desde la mejor de las formas de gobierno a la peor de ellas. Por otra parte, y haciendo un ejercicio comparativo con las doctrinas escatológicas que primarían en Occidente desde la expansión del catolicismo, la teoría política de Polibio es de naturaleza cíclica, no teleológica. Bobbio nos enseñó al respecto que puede trazarse un paralelismo entre lo expuesto por Polibio y otra de las grandes teorías cíclicas de la historia: la de los cursos y recursos de Giambattista Vico. Si bien matizando que "mientras la teoría de Polibio deriva del restringido campo de observación de las ciudades griegas, la de Vico se mueve en toda la historia de la humanidad"26.

Pero si hay una tesis que haya tenido eco en la construcción de la teoría política de Montesquieu y, en consecuencia, de los ideólogos norteamericanos, es su hipótesis sobre el gobierno mixto. La correlación entre esta y la segunda tesis, la teoría de los ciclos, es directa por cuanto aquella demuestra que todas las formas de gobierno simples están destinadas a perecer, por su propia naturaleza, en el transcurso de tres generaciones familiares. Por lo tanto, el gran vicio de toda constitución simple es su falta de estabilidad, de tal forma que in-

\footnotetext{
22 N. Bobbio, La teoría de las formas de gobierno en la historia del pensamiento político, México DF, Fondo de Cultura Económica, 1987 , p. 45.

23 Polibio, op. cit., p. 158

24 Ibidem, pp. 157-158.

Ibidem, pp. 161-164.

26 N. Bobbio, op. cit., p. 49
}

cluso las tres formas rectas de gobierno son en realidad torcidas al carecer de perdurabilidad. El remedio pasará por construir una constitución que sea estable; esto es, la constitución mixta, aplicada, en primer lugar, por el legislador Licurgo en Esparta y, en segundo lugar, por Roma. Dice Polibio en las Historias:

Previendo esto, Licurgo no estableció una constitución simple y homogénea, sino que combinó en ella, a la vez, todas las cualidades y particularidades de las mejores constituciones, con el fin de que ningún componente, al desarrollarse más de lo debido, cayera en los vicios que le eran connaturales y de que, al hacer fuerza por su lado cada uno de ellos, ninguno se inclinara hacia alguna parte y produjera gran desequilibrio, sino que, por el contrario, la constitución se mantuviera equilibrada y compensada largo tiempo, según el principio fijo de las tensiones opuestas $^{27}$.

Así introduce Polibio su gran aportación a la teoría política: la idea de una estructura que organizara mecánicamente la constitución de un pueblo desde el concepto físico de equilibrio. Un proyecto que cobra inusitada validez toda vez que el historiador griego no contaba con las herramientas cartesianas de las que, por ejemplo, dispondría Montesquieu. Esta constitución mixta consiste en un triple mecanismo en el que el rey es frenado por el pueblo, que participa activamente en las labores gubernamentales; pueblo que a su vez es controlado por el senado. Con este engranaje constitucional, los tres poderes quedarían representados -el monárquico por el rey, el democrático por el pueblo y el aristocrático por el senado-y a los mismos tiempos moderados los unos por los otros, en un ejercicio predispositivo de lo que en el siglo XVIII se denominarían mecanismos de control horizontal o checks and balances. Y matizamos ejercicio predispositivo por cuanto, como posteriormente observaremos, aunque ambas ideas estén entrelazadas, no podemos confundir constitución mixta y separación de poderes.

Este mecanismo de constitución mixta fracasaría en Esparta en su fase de crecimiento, pero dotaría a un imperio más fuerte como el romano de la estabilidad política necesaria para su expansión política. Razón por la que Polibio dio el salto de la constitución mixta espartana a la romana, una constitución que se desarrollaría progresivamente desde treinta años después del paso de Jerjes a Grecia hasta alcanzar "su máxima perfección y belleza en los tiempos de Aníbal"28. Este sistema llegaría a la eficiencia plena en el momento en el que los tres componentes de los tres poderes -los cónsules, el senado y los comicios del pueblo- se organizaron y regularon de una forma tan equitativa y conveniente que, según el historiador de griego, "nadie, ni siquiera entre los del país, podría decir con base alguna, si la constitución en su conjunto era aristocrática, democrática o monárquica". Polibio demostraría el equilibrio del artefacto constitucional romano disponiendo las competencias de los tres poderes constitucionales, para terminar afirmando que

\footnotetext{
Polibio, op. cit., p. 165

28 Ibidem, p. 166.
} 
estaban tan armonizados entre sí que "no es posible hablar de un sistema de gobierno mejor que éste"29. Por ello, "la particularidad de este régimen es ser irresistible y llegar a todo lo que se propone" 30 . Roma sería, por lo tanto, el baluarte de los sistemas gubernamentales equilibrados; razón por la que no es de extrañar que cuando, en su Libro XI de Del espíritu de las leyes, Montesquieu plantee su gran teoría constitucional, basada en la separación de poderes y paradigma de los padres de la patria norteamericana, desarrolle con atención la distribución de poderes dadas en la república romana.

\section{Montesquieu: ¿Padre de la Constitución de los Estados Unidos?}

Como venimos trazando durante el presente artículo, no es posible desvincular la originalidad de los mecanismos políticos articulados en la Constitución norteamericana sin hacer referencia al considerado como uno de los padres de la teoría política contemporánea: el barón de Montesquieu. Siguiendo la intención de este artículo, no entraremos a analizar cuestiones biográficas del autor de Del espíritu de las leyes. Lo que aquí interesa es esbozar su doctrina constitucional a fuer del célebre principio de la separación de poderes y con el propósito de responder a las siguientes preguntas: ¿cuál fue la influencia de Polibio en la obra de Montesquieu y qué aportó realmente con lo expuesto en Del espíritu de las leyes en la forma de gobierno planteada por los padres fundadores para la recién creada nación norteamericana?

Un primer asunto por barrer desde esta posición pasaría por conocer la influencia que tuvieron los autores clásicos en la obra de Montesquieu. En este sentido, como extraemos de lo expuesto por el historiador Marshall Davies Lloyd en su artículo Polybius and the Founding Fathers: the separation of Powers ${ }^{31}$, diversas autoridades norteamericanas en el estudio sobre los clásicos han indicado que, cuando citamos al autor en francés, en el fondo estamos invocando a los grandes intelectuales greco-romanos. Así, mientras que Mark L. Hulliung señaló que la gran inspiración del autor francés procedía de clásicos como Aristóteles o Polibio ${ }^{32}$; para Gilbert Chinard, Montesquieu no hizo más que sistematizar y contextualizar las lecciones políticas que nos había dejado la historia antigua ${ }^{33}$. Richard recuerda, en este sentido, que el propio John Adams afirmaba que lo más relevante de autores como Maquiavelo, Harrington, Locke y, particularmente, Montesquieu provenía del rescate teórico de las ideas de los clásicos ${ }^{34}$.

Pero, si Montesquieu apoyó su teoría en lo difundido por el mundo clásico, ¿qué parte de su doctrina bebe de las fuentes greco-romanas y cuál supuso una novedad en

Ibidem, p. 173 .

Idem.

31 M. D. Lloyd, "Polybius and the Founding Fathers: the separation of powers", St Margaret's School, 1, 1998, accessible en línea en http:// www.mlloyd.org/mdl-indx/polybius/intro.htm.

32 M. Hulliung, Montesquieu and the old regime, Los Angeles, University of California Press, 1976, p. 244.

33 G. Chinard, "Polybius and the American Constitution", Journal of the History of Ideas, 1, 1940, pp. 38-58, aquí p. 43.

34 C.J. Richard, op. cit., p. 133. un contexto histórico diferente en el que el germen de la Ilustración envolvía ideológicamente el continente europeo? Para analizar este punto en relación con los componentes constitucionales que aquí desarrollamos, hemos de remitirnos al Libro XI de Del espíritu de las leyes, titulado De las leyes que dan origen a la libertad política en su relación con la constitución. En el primer parágrafo, Montesquieu ya aclara que hay que diferenciar las leyes que otorgan libertad en vínculo con la constitución y aquellas que la hacen en vínculo con el ciudadano tratadas en el siguiente libro de su obra-. Este concepto de libertad política acota intencionalmente la doctrina constitucional de Montesquieu; una idea que debía ser matizada toda vez que la tendencia era asimilar libertad política con el poder del pueblo. Hallamos aquí la primera clave de bóveda con respecto a autores clásicos como Platón, Aristóteles o Polibio: libertad no es democracia, entendiendo esta última de la única forma que se comprendía por aquel entonces; es decir, como la democracia directa de origen griego. La libertad no consiste en hacer lo que el ciudadano quiera, sino que es "el derecho de hacer todo lo que las leyes permiten, de modo que, si un ciudadano pudiera hacer lo que las leyes prohíben, ya no habría libertad, pues los demás tendrían igualmente esta facultad"35. Por lo que este principio está directamente vinculado con el Estado y, más concretamente, con la forma de gobierno. Pero no con una de ellas, pues "la democracia y la aristocracia no son Estados libres por su naturaleza"36. La libertad política se encontrará exclusivamente en los Estados moderados -o en términos de Polibio, en las constituciones mixtas-, $\mathrm{y}$ de estos en aquellos donde no se abusa del poder. Dice Montesquieu: "Para que no se pueda abusar del poder es preciso que, por la disposición de las cosas, el poder frene al poder" ${ }^{37}$. Por lo tanto, de la raíz polibiana de una forma de constitución equilibrada nacerá el principio de la separación de poderes, condición para hablar de un sistema de gobierno donde exista libertad política.

Corresponde matizar que, aunque la doctrina de la separación de poderes está directamente entrelazada con ella, no es sinónimo de la idea clásica de constitución mixta. La diferencia principal radica en que, mientras la doctrina del gobierno mixto se fundamenta en la idea de que cada sector social participe en el gobierno del Estado, la noción de separación de poderes comporta necesariamente la división funcional de los órganos de gobierno y sus integrantes. Aun cuando fuera Montesquieu quien terminó de desarrollarla, no puede obviarse la influencia de Locke en la constitución de la doctrina de la separación de poderes. En este sentido, el filósofo inglés distinguiría entre poder legislativo, que incluiría la facultad de hacer leyes y de juzgar; el poder ejecutivo, cuya competencia sería la ejecución de las referidas leyes; y el poder federativo, potestad de declarar la guerra y la paz. Con todo, la doctrina expuesta por Locke no se constituiría como separación poderes en la medida en que no implicaba división funcional, pues el poder

\footnotetext{
Montesquieu, Del espiritu de las leyes, Madrid, Alianza Editorial, 2003, p. 205.

36 Ibidem, p. 205

37 Idem.
} 
legislativo lo ostentaba el parlamento y el monarca; y el ejecutivo, el monarca y su consejo.

Por lo tanto, fue Montesquieu quien terminó de modular el desarrollo mecánico de la separación de poderes, para lo que aludiría en el sexto capítulo de su obra magna a la constitución de Inglaterra $^{38}$. La tesis del francés, basada en la constitución mixta, se tornará más completa por cuanto anunciará de una forma más escrupulosa que Polibio las incompatibilidades entre los tres poderes del Estado. Poderes que, como todos sabemos y siguiendo la tradición aristotélica, denominará legislativo, ejecutivo y judicial ${ }^{39}$. Los límites para el equilibrio de los poderes transcurren por la siguiente senda:

Cuando el poder legislativo está unido al poder ejecutivo en la misma persona en el mismo cuerpo, no hay libertad porque se puede temer que el monarca o en Senado promulguen las leyes tiránicas para hacerlas cumplir tiránicamente. Tampoco hay libertad si el poder judicial no está separado del legislativo ni del ejecutivo. Si va unido al poder legislativo, el poder sobre la vida y la libertad de los ciudadanos sería arbitrario, pues el juez sería al mismo tiempo legislador. Si va unido al poder ejecutivo, el juez podría tener la fuerza de un opresor. Todo estaría perdido si el mismo hombre, el mismo cuerpo de personas principales, de los nobles o del pueblo, ejerciera los tres poderes ${ }^{40}$.

Más adelante, Montesquieu esbozaría dos ideas que conectan directamente la tradición política clásica y la contextualización institucional que tomaría forma en los debates entre federalistas y anti-federalistas norteamericanos. Así, tras exponer su mecanismo de control horizontal, el autor francés alerta sobre uno de los mayores peligros al erigir una constitución, un defecto que ya se había dado en "la mayor parte de las Repúblicas de la antigüedad" 41 ; a saber, que "el pueblo tenía derecho a tomar resoluciones activas que requerían de cierta ejecución, cosa de la que es totalmente incapaz"42. Luego, si como ya avisaron Aristóteles, Platón y Polibio, la democracia - directa- es una forma de gobierno más, torcida en tanto constitución simple, ¿por dónde pasaría este nuevo sistema de equilibrio que Montesquieu estaba reconstruyendo? La respuesta es por el principio de representatividad, que el autor del Del espíritu de las leyes explicaría de la siguiente manera: "No es necesario, pues, que los miembros del cuerpo legislativo provengan, en general, del cuerpo de la nación, sino que conviene que, en cada lugar principal, los habitantes elijan un representante"43. Con esta idea y siguiendo un proceso material lineal desde las tesis de Platón y Aristóteles sobre las formas de gobierno y la constitución mixta de Polibio, pasando por la separación de funciones de

\footnotetext{
38 Como afirma Publius: "The British Constitution was to Montesquieu what Homer has been to the didactic writers on epic poetry", en "The Particular Structure of the New Government and the Distribution of Power Among Its Different Parts", The Federalist Papers 47, February $1,1788$.

39 Montesquieu, Del espíritu de las leyes, op. cit., p. 206.

40 Ibidem, pp. 206-207.

${ }^{41} \quad$ Ibidem, p. 210.

42 Idem.

43 Ibidem, p. 209
}

Locke, quedaba definido un nuevo sistema político que ya en el siglo XIX se denominaría "democracia formal" -despectivamente en términos marxistas "democracia burguesa"-; esto es, aquella que cumpliera dos requisitos: la separación de poderes y la representatividad de los ciudadanos de la nación.

La prueba del recelo de Montesquieu a la democracia directa en relación con el sistema constitucional griego deriva de lo expuesto en los tres capítulos sobre Grecia del Libro XI de Del espíritu de las leyes. En el primero de ellos, el señor de la Brède exhibe la influencia que en su teoría política tuvo la obra de Aristóteles. Para Montesquieu, el gran problema del macedonio recaería en su desconocimiento sobre el concepto de monarquía. Y esto debido a que Aristóteles, al distinguir cinco formas de Monarquía, no tomó como elemento eje la forma de la constitución, sino "cosas accidentales, como las virtudes o vicios del príncipe, o cosas ajenas a ella, como la usurpación de la tiranía, o la sucesión a ella"44. De ahí que al ignorar la distribución de los tres poderes en el gobierno de uno solo, "los antiguos no podrían hacerse una idea exacta de la Monarquía"45. En realidad, Montesquieu generalizaba al hablar de los autores antiguos, pues, como él mismo sabía, Polibio no ignoró la distribución de los tres poderes en el gobierno. Posteriormente, Montesquieu analiza la monarquía griega con un objetivo claro: refutar la democracia directa. De esta manera, en estas monarquías el príncipe tenía el poder ejecutivo y el legislativo o, al menos, una parte del legislativo, pero no el judicial ${ }^{46}$. Y aquí es donde residía el problema, pues al disponer el pueblo de la legislación en sus manos, "podía aniquilar a la realeza por el menor capricho, como lo hizo en efecto" ${ }^{\prime 4}$. En conclusión, argumenta Montesquieu, su problema fue que "no concibieron la verdadera distribución de los tres poderes en el Gobierno de uno solo, sino solamente en el Gobierno de varios" $" 48$.

El ciclo no funcionaría de la misma manera en Roma. Para concluir el Libro XI y, previa influencia de Polibio, Montesquieu contextualiza la teoría sobre la separación de poderes aterrizando en Roma. Así, el equilibrio gubernamental no regiría del mismo modo en la monarquía que en la república. La constitución monárquica romana, en el período que osciló entre el primer rey Rómulo (753-717 a.C.) y Tarquino Prisco (616-578 a.C.) era un buen sistema por cuanto se podía calificar como monárquico, aristocrático y popular. La clave se hallaba en el equilibrio de funciones entre los poderes. Sin embargo, esto cambió con el reinado de Servio Tulio (578-534 a. C.), pues al no participar el senado en su elección, se debilitó el poder legislativo y aumentó el poder del pueblo. Esta dinámica de ruptura del equilibrio degeneró aún más con la llegada al poder de Tarquinio el Soberbio (534-509 a. C.), quien no se hizo elegir ni por el senado ni por el pueblo ${ }^{49}$, suscitando el mayor de los pecados en una constitución: la detención de los poderes en un

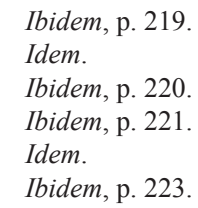


solo hombre. Con la expulsión de Tarquinio, llegó la república. Para Montesquieu, el terreno estaba abonado para el aterrizaje de la democracia. Y aunque en inicio la constitución se estabilizó contrabalanceando al pueblo ante el exceso de poder del consulado y configurando un sistema mixto, la democracia terminó excluyendo a los patricios y al senado del poder legislativo. Este fraccionamiento supuso un daño a la libertad de la constitución romana $^{50}$, y ello pese a que la intención se dirigiera hacia el favorecimiento de la libertad del ciudadano; sin embargo, "esta se perdió con aquella" 51 .

El amplio desarrollo contextual derivado del análisis de siete siglos de constituciones políticas en Roma nos lleva a pensar que la influencia de la teoría política clásica en Del espíritu de las leyes fue esencial. Tan sustancial, de hecho, que, en el núcleo de la crítica al funcionamiento de la constitución republicana, Montesquieu cita las Historias de la Polibio ${ }^{52}$. No es casualidad que en el Libro que establece el principio de la separación de poderes y los checks and balances se cite la obra más relevante del historiador griego. Un debate que venía germinándose en el movimiento que se dio a llamar la "tradición republicana", nacido, como expresa Richard, con la obra de teóricos políticos florentinos como Guicciardini o Maquiavelo. No en vano, este último construyó el alegato contra las formas simples de gobierno del Discurso sobre Tito Livio con base en las aportaciones de Polibio ${ }^{53}$. La influencia de Maquiavelo llegó a Inglaterra a través del filósofo James Harrington y su obra La República Oceana, donde, como explica Juan José Solozábal, se retomaban las ideas clásicas de Polibio sobre el gobierno mixto ${ }^{54}$. A su vez, Harrington influyó en las doctrinas de los filósofos ingleses del siglo XVII, con Blackstone y Locke a la cabeza, repercutiendo con posterioridad en la teoría política de los filósofos franceses del siglo XVIII; no sólo en el caso de Montesquieu, sino también en el Rousseau. Toda esta amalgama de ideas en relación con la organización constitucional, con un origen preciso en Aristóteles so perfeccionamiento por Polibio, terminaría tomando tierra en la Europa que albergaba la transformación social consistente en trasladar la soberanía divina del monarca a la soberanía nacional del pueblo. Este binomio, soberanía nacional-separación de poderes, se plasmaría en papel por primera vez en la Constitución norteamericana de 1787, donde el preámbulo comenzaba por el célebre "We the People of United States" para continuar con los tres primeros artículos que, en clara correlación y en orden no casual, establecerían las competencias de los tres poderes: legislativo, ejecutivo y judicial.

\section{El oxímoron: la nueva constitución que nace en Polibio}

Con Polibio y Montesquieu -amén de Maquiavelo y Locke- tenemos las herramientas precisas para comen-

Ibidem, p. 236.

Idem.

Ibidem, p. 230.

C.J. Richard, op. cit., p. 127

54 Cf. J.J. Solozábal, "Sobre el principio de la separación de poderes", Revista de estudios políticos, N²4, 1981, pp. 215-234, aquí p. 219. zar a trazar un mapa de la configuración política norteamericana, modelada al albur de los debates sobre la Constitución de 1787; una discusión pública que alcanzó una profundidad mayúscula en relación con el significado y el funcionamiento de la democracia representativa. La disputa situó en un lado del tablero a los federalistas $\mathrm{y}$ en el otro a los antifederalistas. En este sentido y en relación con el análisis de presente artículo, ambas facciones compartían un conjunto de principios doctrinales que operaban en conexión directa con la teoría política clásica. Sin embargo, otras ideas procedentes de Grecia y Roma serían, precisamente, el objeto de polémica entre federalistas y antifederalistas. Expondremos, en primer lugar, los principios concomitantes, que a nuestro juicio pueden resumirse en tres puntos.

Un primer lugar común en ambas facciones pasaba por la concepción del hombre entendido como ser corruptible por naturaleza; esto es, la idea en virtud de la cual los individuos no actúan movidos por el bien público, sino por intereses personales y partidistas. El fundamento principal por el que los autores norteamericanos entendieron que la Constitución tenía que partir de la concepción del hombre corruptible se encuentra en los escritos antigubernamentales de los opositores radicales de la Inglaterra de finales del siglo XVII y principios del XVIII. Baylin destaca, en este sentido, la figura del vizconde de Bolingbroke, quien, en el contexto del gobierno del Primer Ministro Walpole, acuñó el término despectivo de "robinocracia" a fin de explicar la corrupción de "una forma de gobierno, en la que el primer ministro mantenía las apariencias de los procedimientos constitucionales cuando, en realidad acaparaba la totalidad del poder gubernativo" "55. Estas críticas de autores como Bolingbroke a los gobiernos de Walpole o Gibbon tuvieron una influencia escasa en Inglaterra; sin embargo, en las colonias norteamericanas llegaron a ser poderosamente populares e influyentes, tanto que los padres fundadores atribuyeron la nueva tiranía a la degeneración que provocaba la mezcla de la constitución inglesa ${ }^{56}$. Así, dadas "la necesidad de crear de la noche a la mañana nuevos sistemas de representación" 57 y los conflictos existentes entre el ejecutivo y el legislativo, se tendió a "implantar una representación regular y responsable" y limitar la "influencia discrecional de cualquier grupo que estuviera en el poder" 58 . El prestigio de estos comentarios de los opositores ingleses en contra de la corrupción gubernamental tomó forma en los Estados Unidos en la necesidad de establecer un sistema que impidiera su perversión interna.

En segundo lugar, al comienzo del conflicto entre colonos e ingleses, la idea de constitución de aquellos todavía intervenía desde los parámetros tradicionalistas. Como sus predecesores ingleses, el término constitución no estaba vinculado a un documento escrito, ni siquiera a una declaración formal de derechos, sino que, en clara correlación con la politeia de Aristóteles, los colonos pensaban en ella en tanto orden constituido

\footnotetext{
B. Bailyn, op. cit., pp. 60-61

56 C.J. Richard, op. cit., p. 127.

57 B. Bailyn, op. cit., p. 62.

58 Idem.
} 
de instituciones de gobierno, leyes y costumbres. Así, nos dice Baylin, "John Adams escribía que una constitución política era como «la constitución de un cuerpo humano, $[\ldots]$ una cierta contextura de los nervios, fibras y músculos»" "99, que para el padre fundador "podrían denominarse con toda propiedad stamina vitae, o partes esenciales o fundamentales de la constitución, sin las cuales la vida misma no podría perdurar un instante más" ${ }^{60}$. Posteriormente, y en sincronía con el movimiento revolucionario francés, en los debates entre federalistas y antifederalistas la idea aristotélica evolucionaría hacia un concepto diferente de constitución: aquella que garantizara, por escrito, el armazón político de la nación.

En tercer lugar, federalistas y antifederalistas compartían un fundamento esencial con respecto a la constitución: la idea de que su fin último es lograr estabilidad. Baylin acentúa, en este sentido, lo expuesto por James Otis en su obra Rights of the British Colones en relación con el debate sobre la legitimidad de las constituciones. Decía Otis: "La constitución de un Estado debe ser estable; y puesto que aquella ha sido establecida primera por la nación, la cual delega luego en ciertas personas del poder legislativo, las leyes fundamentales se hallan excluidas de esa facultad delegada" ${ }^{61}$. Recordemos, el planteamiento en virtud del cual la característica sustancial de una constitución se encuentra en su estabilidad es un principio vital en las Historias de Polibio. Como Platón y en clara sintonía con su visión cíclica, Polibio no albergaba la posibilidad de una constitución que operara ad eternum. Incluso el Estado romano estaba sujeto, a pesar de su excelencia, a la ley natural del nacimiento, evolución y muerte; por lo que el propósito de una constitución pasaba por su estabilidad y no por su perpetuidad.

Pero, si estos tres puntos concomitantes de las teorías federalistas y antifederalistas nos acercan a los caminos hacia Grecia y Roma, las siguientes preguntas a responder serían: ¿qué diferencias fundamentales existían entre ambas facciones y qué aspectos de la doctrina vencedora, la federalista, se asentaban en Polibio y cuáles transformaron los preceptos clásicos? Con respecto a la primera de estas preguntas, aunque las dos doctrinas partieran del principio de corrupción individual, la diferencia principal radicaba en que, mientras los antifederalistas concentraban su desconfianza en la figura del representante y creían ciegamente en la inocencia del pueblo, los federalistas suponían la primacía del individuo y su capacidad de elección de los representantes por encima del pueblo como colectivo. De estas dos concepciones puede inferirse que los antifederalistas defendieran mecanismos de control de vertical y los federalistas de control horizontal, pues estos, aunque compartían con aquellos la preocupación por un abuso de poder de un gobierno fuerte, pensaban que la solución no pasaba por establecer un gobierno sin poder, sino un gobierno fuerte que estuviera controlado por mecanismos horizontales que garantizasen la división interna y la supeditación mutua entre instituciones. Encontramos

\footnotetext{
$59 \quad$ Ibidem, p. 79.

60 Idem.

61 Ibidem, p. 182
}

en los federalistas el principio fundamental, derivado de Platón, Aristóteles y Polibio ${ }^{62}$, en virtud del cual la estructura política de la nación tenía que protegerse de la "tiranía de la mayoría". En este sentido, Richards ahonda en la influencia de Adams, quien expresó que sólo a través de un equilibrio adecuado de los poderes y de las ideas modernas de representación, los Estados Unidos podrían escapar del tumultuoso desorden que provocaría "el poder de la ecclesia"63. El propio Adams, en su obra A Defence of the Constitutions of Government of the United States of America, haría referencia al legado clásico en la constitución del gobierno mixto, derivado de los escritos de Platón, Aristóteles, Plutarco y, por supuesto, Polibio ${ }^{64}$. Como explica Martínez Maza: “los federalistas sostuvieron (...) que cuanto más perfecta y ponderada fuera la combinación de fórmulas simples de gobierno (monarquía, aristocracia, democracia), mayor estabilidad lograría el Estado" $"$.

En El Federalista se esbozan notables ejemplos de este ejercicio consistente en incorporar a la idea clásica gobierno mixto, la idea moderna separación de poderes con el objeto de confrontar la temida "tiranía de la mayoría”. Así, en el artículo n. ${ }^{\circ} 51$ de El Federalista, Publius señala que una república no debe proteger a su sociedad únicamente contra la opresión de sus gobernantes, sino que también debe amparar a una parte de esta contra la injusticia de la mayoría. El argumento de Publius es que, en el momento en que la mayoría se une por un interés común, los derechos de la minoría entran en riesgo ${ }^{66}$. Al mismo tiempo, los federalistas comprendieron que, junto control del abuso de poder por parte de las mayorías, debían vigilar el abuso de poder de los gobernantes; y ello por cuanto, como se señala en artículo n. ${ }^{\circ} 47$ de $E l$ Federalista, la acumulación de los tres poderes en las mismas manos ya sea de uno, pocos o muchos, y ya sean hereditarios, autoimpuestos o electivos, lleva, precisamente, a la tiranía ${ }^{67}$. Por lo tanto, la base de los federalistas es la siguiente: un gobierno fuerte, independiente a los deseos de la mayoría y a su vez internamente dividido, podría superar ambos problemas, tanto el del abuso del poder como el de la tiranía de la mayoría. Madison, Hamilton y Jay serían quienes plasmasen este principio en la teoría constitucional norteamericana. Como se expone en el artículo n. 51 de El Federalista: Como todas

62 Publius cita a Polibio en El Federalista: "To these examples might be added that of Carthage, whose senate, according to the testimony of Polybius, instead of drawing all power into its vortex, had, at the commencement of the second Punic War, lost almost the whole of its original portion", en "The Senated Continued", The Federalist Papers, 63, 1788.

63 C.J. Richard, op. cit., p. 138.

64 J. Adams, The Works of John Adams, vol. 5 (Defence of the Constitutions Vols. II and III), 1851, accesible en línea en: https://oll.libertyfund.org/titles/adams-the-works-of-john-adams-vol-5-defence-ofthe-constitutions-vols-ii-and-iii.

65 C. Martínez Maza, "La anaciclosis polibiana, principio de autoridad durante el periodo constituyente de los Estados Unidos", Gerión, 37, 2019, pp. 473-487, aquí p. 476.

66 Publius, "The Structure of the Government Must Furnish the Proper Checks and Balances Between the Different Departments", The Federalist Papers 51, February 8, 1788.

67 "The Particular Structure of the New Government and the Distribution of Power Among Its Different Parts", The Federalist Papers 47, February 1, 1788. 
estas disposiciones externas se muestran inadecuadas, el defecto debe ser subsanado configurando de tal manera la estructura interna del gobierno que sus diversas partes integrantes pueda ser el medio de mantenerse unas a otras en el lugar que les corresponde. Ha de lograrse que la ambición contrarreste a la ambición ${ }^{68}$.

En esta última sentencia apodíctica de Publius podemos ver asomarse a Montesquieu -“es necesario que el poder frene al poder"- previo paso de este por Polibio. Será, sin lugar a duda, la base sintáctica contemporánea de la implantación del principio de separación de poderes y el mecanismo de checks and balances; un cimiento que, aunque con sus influencias dadas, tendrá una nueva característica en los padres de la patria: para que los mecanismos de frenos y contrapesos produzcan el efecto de control horizontal necesario tendrán que cumplirse tres condiciones. En primer lugar, que el poder quede dividido funcionalmente entre el legislativo, ejecutivo y judicial; una división que, como hemos ido bosquejando, parte de Platón y Aristóteles, se perfecciona con Polibio, transita por Locke y aterriza en Montesquieu. En segundo lugar, y a nuestro juicio, el aspecto esencial para comprender la potencia de los padres fundadores por cuanto significaba la evolución sistemática de la separación de poderes expuesta en Del espíritu de las leyes, la condición de que cada uno de estos poderes se configuraran según principios ajustados a sus distintas funciones, de tal manera que los mandatos y modos de elección de los diversos poderes fuesen distintos a fin de evitar el conflicto de intereses. En tercer lugar, y en clara concordancia con la diversidad funcional expuesta por Polibio en relación con las competencias de los tres poderes en Roma, la exigencia consistente en que todos los poderes hubieran de participar en la toma de decisiones - con diversas potestades de veto-.

Esta configuración política, asentada en la separación de poderes e ideada por los federalistas, germinaría en los tres primeros artículos de la Constitución de 1787, que deslindan, en este orden, las competencias del legislativo, del ejecutivo y del judicial. Para los padres fundadores, el primer poder a frenar sería, paradójicamente, aquel que representa a la nación: el legislativo. De ahí que el Congreso quedara dividido en dos cámaras: la Cámara de Representantes y el Senado. No en vano y como nos explica Baylin ${ }^{69}$, la revolución norteamericana se inició ante la decisión del Parlamento inglés de fijar impuesto a las colonias tras la crisis que asoló a la isla como consecuencia de la Guerra de los Siete Años; situación que originó el célebre lema No taxation without representation. Hay que comprender, por lo tanto, que los colonos norteamericanos se sublevaron contra el parlamento, razón por la que el primer objetivo del sistema de check and balances pasaba por frenar el omnímodo poder del legislativo. En segundo lugar, y en lo que respecta al poder ejecutivo, se estableció un mandato de cuatro años por medio de un sistema de elección indirecta consistente en que los ciudadanos de los Estados seleccionaran a los electores que se encargaban de la elección del presidente. Las ideas de representatividad y separación de poderes se verían reflejadas en la diferencia de simbolización entre el legislativo y el ejecutivo: mientras aquel representaba los intereses locales -Cámara de los Representantes-y estatales -Senado-, el presidente era el sujeto sobre el que recaía la representación del conjunto de la nación. Además, para garantizar la tercera de las condiciones de funcionamiento del sistema de checks and balances, se dotó al ejecutivo de la potestad de vetar la legislación del Congreso a fin de aplacar los abusos de la mayoría; no obstante, este veto no operaría como absoluto por cuanto las dos cámaras podrían superarlo con una mayoría de dos tercios. En cuanto al poder judicial, los padres de la patria tomaron la concepción planteada por Montesquieu en Del espíritu de las leyes al considerarlo como el poder más débil en virtud de su dependencia política del ejecutivo. Al respecto, Hamilton argüiría en El Federalista, n. ${ }^{\circ} 78$, que se trata del más débil de los tres poderes. No en vano, Montesquieu diría que el judicial es un poder "invisible y nulo". Sin embargo, la novedad de los federalistas pasaría por reivindicar que los tribunales de justicia tuvieran el control de constitucional de las leyes.

En conclusión, el éxito de los padres de la patria a la hora de configurar el sistema constitucional norteamericano residió en su habilidad para contextualizar el principio de la separación de poderes, desarrollado por Montesquieu previo paso por Locke, para, en su plasmación constitucional, perfeccionar el sistema proporcionándole unas herramientas que operarían como elemento catalizador del éxito práctico que supuso una constitución que sigue vigente doscientos treinta dos años después de su promulgación. Pero esta línea directa que pretende establecerse entre Maquiavelo, Locke, Montesquieu y los colonos norteamericanos se torna como una idea metafísica si parte de un planteamiento en virtud del cual la separación de poderes se entiende surgida ex nihilo, in media res, en los siglos XVII y XVIII, y no como un efecto de un reflejo de la anamnesis que, avanzando en un proceso material-histórico, hunde sus raíces en los diálogos platónicos y los textos de Aristóteles para adquirir orden estructural en la figura de Polibio. Una circunstancia que tuvieron presente los padres fundadores de los Estados Unidos de América.

\footnotetext{
68 Publius, "The Structure of the Government Must Furnish the Proper Checks and Balances Between the Different Departments", The Federalist Papers 51, February 8, 1788.

${ }^{69}$ Publius, "The Judiciary Department", The Federalist Papers, 78.
} 


\section{Bibliografía}

Adams, J., The Works of John Adams, vol. 5, Defence of the Constitutions Vols. II and III, 1851, (https://oll.libertyfund.org/titles/ adams-the-works-of-john-adams-vol-5-defence-of-the-constitutions-vols-ii-and-iii)

Bailyn, B., Los orígenes ideológicos de la revolución norteamericana, Madrid, Tecnos, 2012.

Bobbio, N., La teoría de las formas de gobierno en la historia del pensamiento político, México DF, Fondo de Cultura Económica, 1987.

Bueno, G., El sentido de la vida: seis lecturas de filosofía moral, Oviedo, Grupo Helicón, 1999.

-, “QQué es la democracia? [1]”, El Catoblepas, 109, 2011 (http://nodulo.org/ec/2011/n109p02.htm).

Chinard, G., "Polybius and the American Constitution", Journal of the History of Ideas, 1, 1940, pp. 38-58.

García de Quevedo, Ma. D., "La antigua Roma y la ideología de la revolución”, Gerión, 23, 2005, pp. 329-343.

Hulliung, M., Montesquieu, and the old regime, Los Angeles, University of California Press, 1976.

Levine, J.M., The battle of the books: history and literature in the Augustan, Ithaca (Nueva York), Cornell University Press, 1994.

Lloyd, M. D., "Polybius and the Founding Fathers: the separation of powers", en St Margaret's School, 1, 1998 (http://www. mlloyd.org/mdl-indx/polybius/intro.htm).

Martínez Maza, C., "Democracia ateniense vs. revolución americana: el rechazo al paradigma clásico", en Potestas: Religión, poder y monarquía. Revista del Grupo Europeo de Investigación Histórica, 3, 2010, pp. 215-226.

-, "La anaciclosis polibiana, principio de autoridad durante el periodo constituyente de los Estados Unidos", Gerión, 37, 2019, pp. 473-487.

Montesquieu, Del espiritu de las leyes, Madrid, Alianza Editorial, 2003.

Polibio, Selección de historias, Madrid, Ediciones Akal, 1986.

Publius, "The Particular Structure of the New Government and the Distribution of Power Among Its Different Parts", The Federalist Papers, 47, February 1, 1788.

-, "The Structure of the Government Must Furnish the Proper Checks and Balances Between the Different Departments", The Federalist Papers, 51, February 8, 1788.

-, "The Senate Continued", The Federalist Papers, 63, 1788.

-, "The Judiciary Department", The Federalist Papers, 78.

Reguera, M., "Patriotismo y romanidad en la revolución americana. El patriotismo ilustrado y su tránsito al moderno nacionalismo", Encuentro en Catay, No26, 2012, pp. 330-341.

Richard, C.J., The founders and the classics: Greece, Rome, and the American enlightenment, Cambridge, Harvard University Press, 1995.

Solozábal, J.J., "Sobre el principio de la separación de poderes”, Revista de estudios políticos, №24, 1981, pp. $215-234$.

Wood, G.S., The creation of the American republic 1776-1787, Williamsburg, Chapel Hill, 1969. 